\title{
Research on FLD of H340LAD Niobium Alloy Steel Based on the Finite Element Method
}

\author{
Liwen Tian", Changfeng Men ${ }^{2}$ \\ ${ }^{1}$ Tianjin University of Technology and Education, Tianjin Key Lab of High Speed Cutting and Precision Machining \\ No.1310, Dagu South Road, Hexi District, Tianjin 300222, China \\ ${ }^{2}$ Tianjin University of Technology and Education, No.1310, Dagu South Road, Hexi District, Tianjin 300222, China
}

\begin{abstract}
The Forming Limit Diagram can simply and intuitively reflect the form ability of the sheet. In this paper based on the finite element simulation software Dynaform, combined with maximum load judgment criterion and the strain path judgment criterion, obtained ultimate strain data and accurately obtained H340LAD niobium hsla steel forming limit diagram. Using finite element simulation method is more convenient to study the material parameters (yield function index m, thick anisotropic index $r$, hardening index $n$ ) on the influence law of forming limit curve, provided the basis for study of FLD.
\end{abstract}

Keywords: Finite element simulation, FLD, H340LAD niobium hsla steel, material parameters, forming limit curve

\section{Introduction}

In industrial production, sheet metal stamping has become an irreplaceable production technology, the products are widely used in automobile manufacturing, electronics and aerospace and other fields. Sheet metal forming limit, is a kind of performance indicators, which can reflect the maximum deformation degree, in the process of sheet metal stamping deformation.

Forming Limit Diagram (FLD) is the most simple and intuitive method to Judge and measure the performance of sheet metal forming, mark the ultimate strain in the coordinate system and connect its into line can obtain the Forming Limit Diagram [1].Because the Forming Limit Diagram can simply and intuitively reflect the Form ability of the sheet [2], it has become a effective tool to solve the problem in sheet stamping. Therefore, research the factors that influences the Forming Limit Diagram have great practical significance.

In this paper, according to the sizes, designed with 9 groups of sample, one by one to the finite element simulation, it use and change the strain path method to get the ultimate strain, obtain the forming limit curve based on the simulation, and research the Yield function index parameter $\mathrm{m}$, thick anisotropic index $\mathrm{r}$ and hardening index $\mathrm{n}$, get the influence law of forming limit cure.

\section{Method of Numerical Simulation for Sheet Metal FLD}

\subsection{The shapes and sizes of sheet metal}

In this paper, materials is adopted the H340LAD niobium alloy steel which was developed by masteel. The Niobium Micro alloyed Steel is a kind of high strength steel used in cold forming. It has a high strength and a high difficulty in rolling. Currently, this kind of steel usually in the field of car and electrical Household appliances, some stamping structure with a higher requirement of draw ability and strength [3]. Its chemical composition is shown in Table 1.1:

Table 1.1 Material chemical composition (unit, \%)

\begin{tabular}{|c|c|c|c|c|c|c|}
\hline $\mathrm{C}$ & $\mathrm{Si}$ & $\mathrm{Mn}$ & $\mathrm{Nb}$ & $\mathrm{P}$ & $\mathrm{S}$ & $\mathrm{N}$ \\
\hline 0.05 & 0.17 & 1.4 & 0.13 & 0.01 & 0.0021 & 0.006 \\
\hline
\end{tabular}

The method is used to change the specimen width. According to the size of the national standard recommended design 9 groups of samples, the diameter of the sample is $180 \mathrm{~mm}$, the width range from $20 \mathrm{~mm}$ to $180 \mathrm{~mm}$. The detail size of the sample is shown in Fig.1.Because the width is different, so the stress state in the sample is also different[4].In the process of simulation, the stress state from one-way gradually transition to two-way tensile stress, then obtained the ultimate strain in different strain paths and complete forming limit diagram.

\subsection{The establishment of the finite element model}

According to the geometry of FLD sample size in Fig.1, Using three-dimensional modeling software UG to model the punch, die, pressure to coil and sheet metal. Exporting the "igs" format files, then imported it into the finite element analysis software Dynaform and divided of grid, the maximum size of grid was $3 \mathrm{~mm}$, minimum size was1 $\mathrm{mm}$ the result is shown in Fig.2.

The forming limit diagram by finite element numerical simulation supposed that Punch Stroke is $50 \mathrm{~mm}$, punch stroke should be much larger than the experimental value, the virtual speed of blank holder is $2500 \mathrm{~mm} / \mathrm{s}$ and the virtual speed of Punch is $3500 \mathrm{~mm} / \mathrm{s}$ and the blank holder force, we use the actual test force with $2000 \mathrm{KN}$.it ensure that material of the flange portion will not flow in the process of molding [5].

In finite element simulation, the type of material was selected 36 parameters of anisotropic elastic-plastic material model. The material performance parameters were needed to input as follows: density, elastic modulus $\mathrm{E}$ and 


\section{International Journal of Science and Research (IJSR)

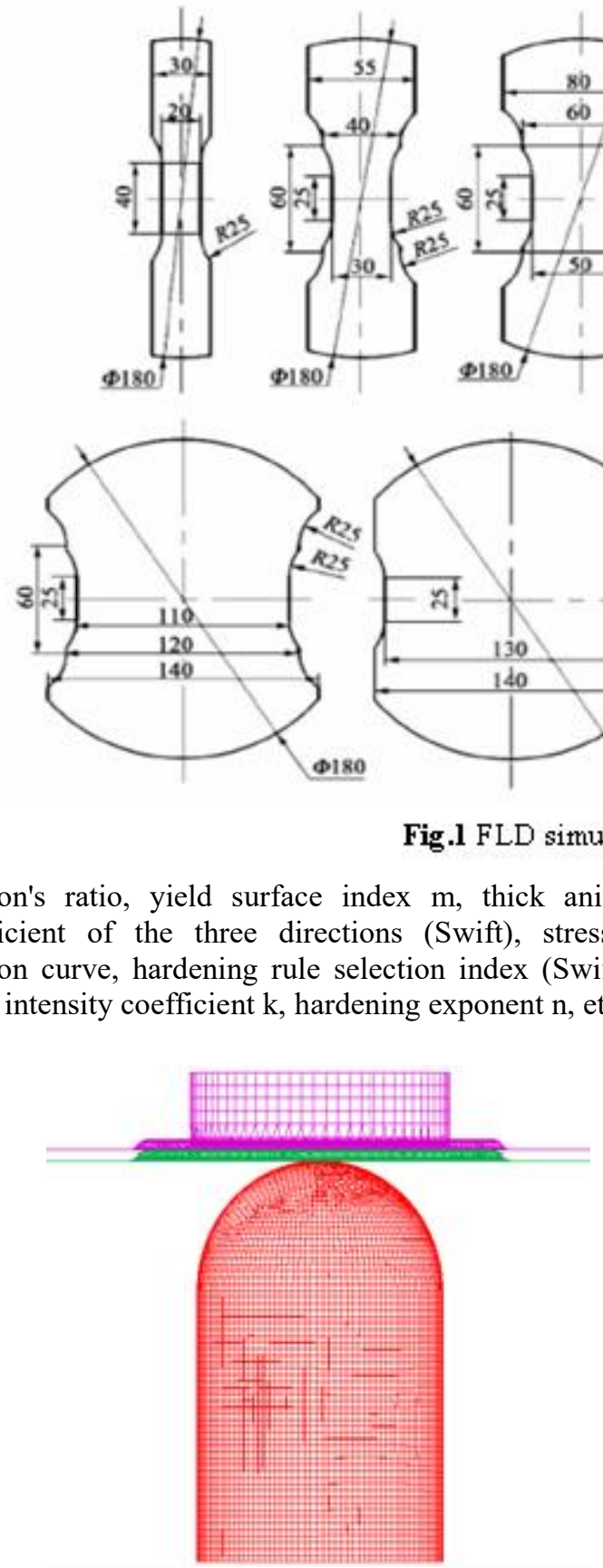
input intensity coefficient $\mathrm{k}$, hardening exponent $\mathrm{n}$, etc.
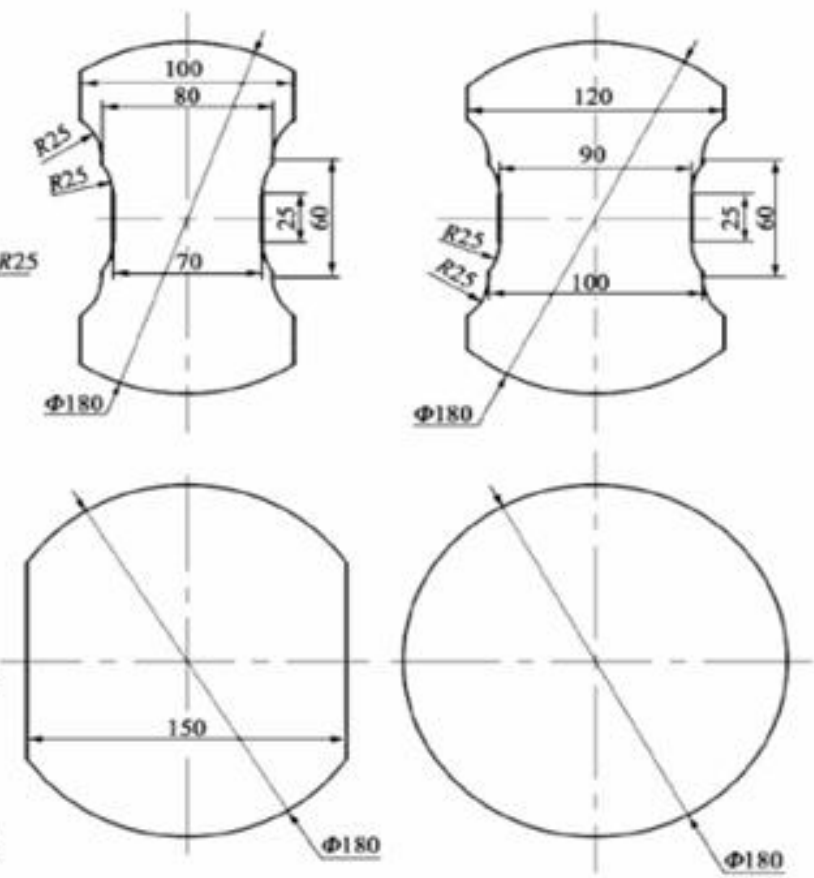

180
Figure 2: FLD finite element geometry model

\subsection{Limit strain criteria}

In the post processor from the Dynaform, it showed the forming limit diagram and thickness variation of sheet metal in the stamping process, and each point's maximum and minimum strain value in every step. But through these data from simulation, it can't judge when the sheet metal well neck or break in the formation process[6].

Maximum load judgment method: through the curves of punch load and stroke. As shown in Fig.3, in the stamping process, with the gone the load in the punch gradually rise, then get the peak, after falling suddenly, sheet metal necking happened and then break at this time. Find the punch pressure peak time and which step it in, read the maximum principal strain unit's maximum and minimum principal strain value, then get the ultimate strain of this sheet. This

poisson's ratio, yield surface index $\mathrm{m}$, thick anisotropic relation curve, hardening rule selection index (Swift) need

\section{Volume 4 Issue 12, December 2015}




\section{International Journal of Science and Research (IJSR) \\ ISSN (Online): 2319-7064}

Index Copernicus Value (2013): 6.14 | Impact Factor (2014): 5.611

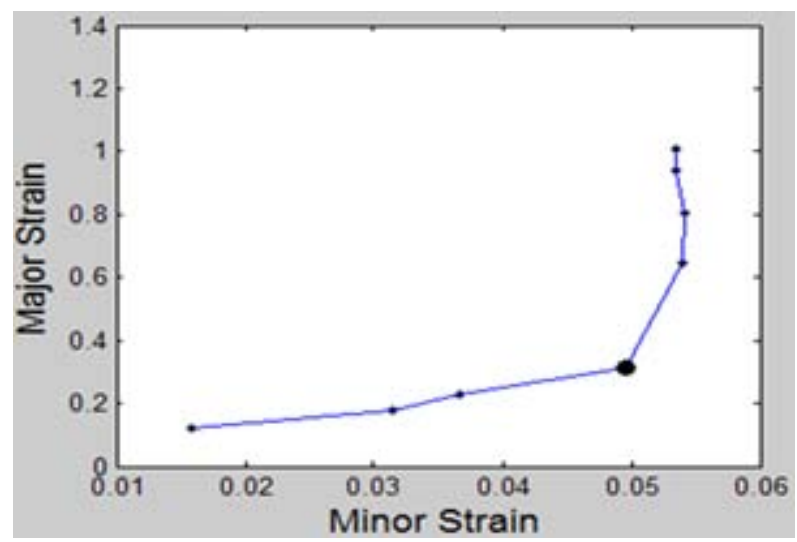

Figure 4: Necking point judging process

\subsection{The results of simulation}

The simulation of FLD is shown in Fig.5. FLD is tension and compression area on the left side of the part, in accordance with a function, on the right side is tension and tension district, in accordance with cubic curve.

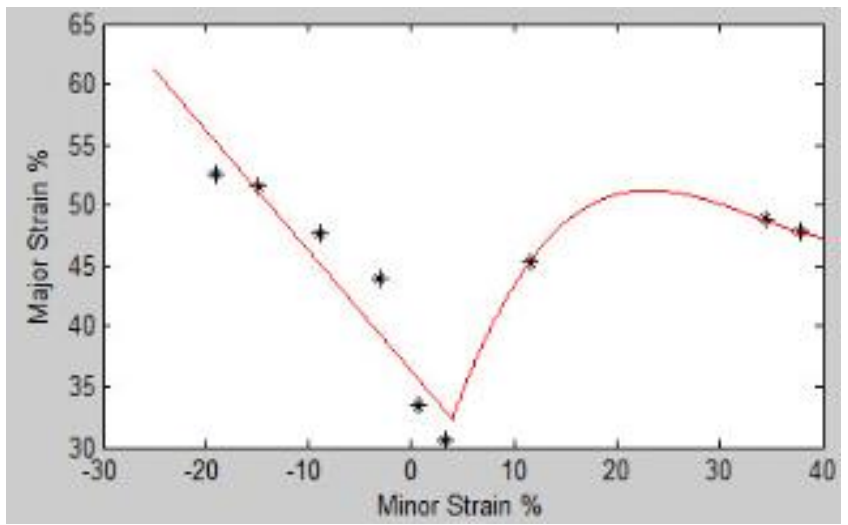

Figure 5: The FLD of simulation

\section{The influence of material parameters on FLD}

\subsection{The influence of yield function index $m$ on FLD}

For BCC crystal and FCC crystal, 6 and 8 is the recommended index value in the yield. However, the value in H340LAD NB micro shows.

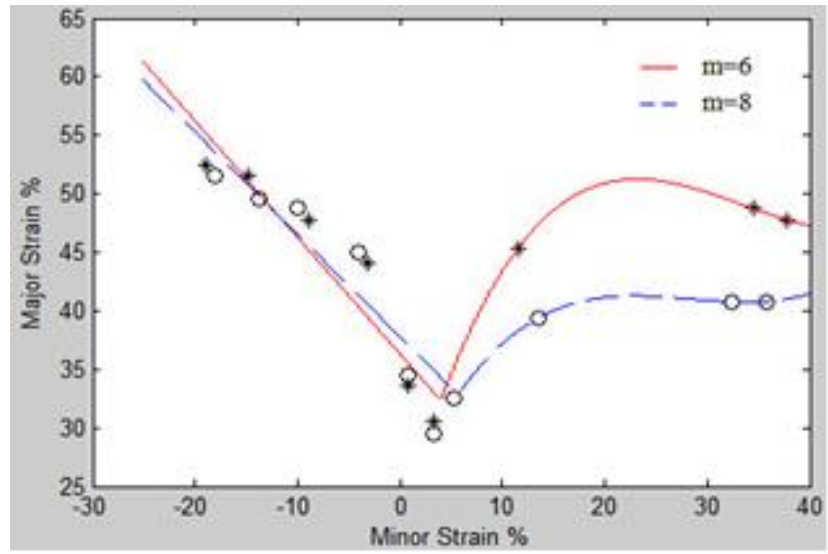

Figure 6: $m$ value on the influence of FLD
In the condition that other material parameters is invariable, when the yield function index parameter $m=6$ and $m=8$, the influence law to the result of FLD. The influence of $m$ value on the FLD left side is small, while on the right side, FLD curve along with the increase of $\mathrm{m}$ value the result is shown in Fig.6.

\subsection{The influence of thick anisotropic index $r$ on FLD}

Fig. 7 shows in the condition that other materials is invariable, when thick anisotropic index $r=0.8, r=0.9$ and $r=1.0$, the influence law to the result of the FLD. In the single area, the change of $r$ value has almost no effect on the results, while in the dual zone, as the $r$ value tends to be 1.0 , the higher the forming limit curve. This suggests that in sheet metal two-way stretch, anisotropy is more significant, the forming limit is smaller, the forming performance is worse.

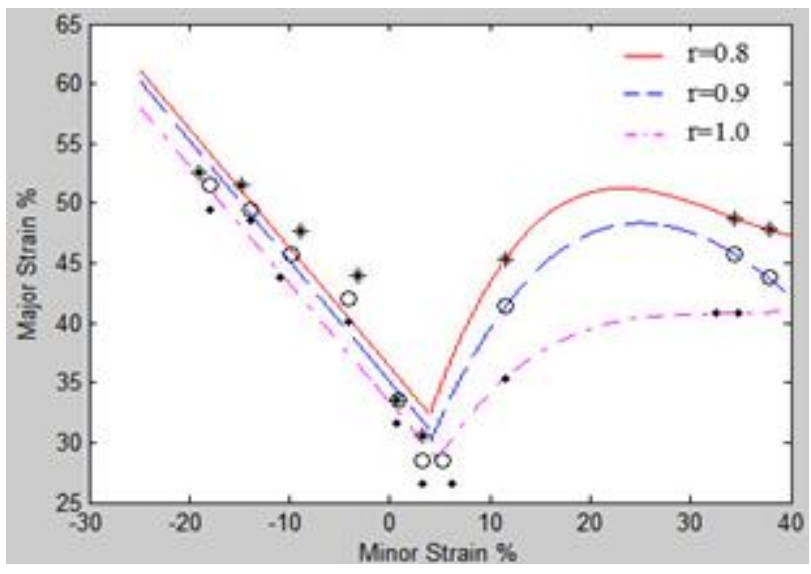

Figure 7: r value on the influence of FLD

\subsection{The influence of sheet metal hardening index $n$ on} FLD

Fig. 8 shows in the condition that other materials is invariable, when sheet metal hardening index $\mathrm{n}=0.16, \mathrm{n}=0.18$ and $\mathrm{n}=$ 2.0, the influence law to the result of the FLD. The forming limit curve rising with the hardening exponent $\mathrm{n}$ increase. Because with value $\mathrm{n}$ increase, the material strain strengthening effect also improve, and then make the strain distribution to be homogeneous.

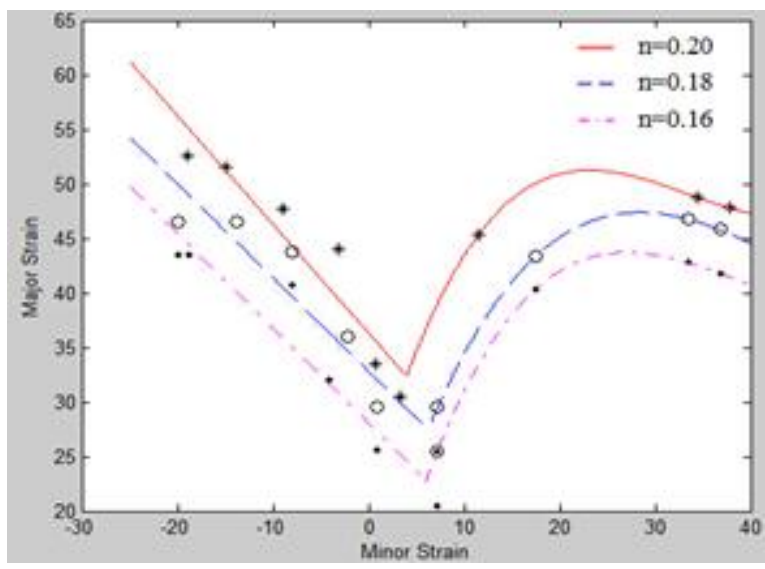

Figure 8: $n$ value on the influence of FLD 


\section{International Journal of Science and Research (IJSR) \\ ISSN (Online): 2319-7064}

Index Copernicus Value (2013): 6.14 | Impact Factor (2014): 5.611

\section{Conclusion}

1) The numerical simulation for the forming limit curve should be used two criteria: on the left side of the tension and compression zone by means of the criterion of maximum load judgment, on the right side of the tension and tension zone we usually use the strain path judgment criteria. Comprehensive two criteria, can accurately obtain H340LAD niobium alloy steel is the ultimate strain of the data.

2) The basis of material mechanical parameters have great influence on FLD. The FLD is along with the rising of the thick sheet of Thick anisotropic index $r$ and Yield function index $\mathrm{m}$ decreases, but decreases with the increase of hardening exponent $n$.

\section{Acknowledgement}

This work is supported by Development Program for Outstanding Young Teachers in TianJin, Tianjin science and technology innovation system and the condition of platform projects, Development Foundation of Tianjin University of Technology and Education Tianjin, China under Grant RC14-39, 14TXGCCX00011, KJ12-13, KJY12-12respectively

\section{References}

[1] Yi.Li, The Theoretical Prediction and Numerical Simulation of AZ31 Forming Limit Diagram of The Magnesium Alloy Sheet in the Hot State[D], Shan Xi: Taiyuan University of Technology, 2013, pp.20-25.

[2] Xiao.Zhang, Theoretical Prediction and Numerical and Numerical Simulation of AZ31 Forming Limit Diagram of The Magnesium Alloy Sheet in the Hot State[D], Shan xi:Tai yuan University of Technology, 2013, pp.40-48

[3] Zhenyong.Liu, Yaguang.Li, Dayong.li, Limit Experiment and Numerical Simulation of 5754-H111 Sheet Metal Forming Aluminum[J], Forging Technology, 2014, pp. $35-40$

[4] Ran.Gu.Measurement and Analysis of Limit Forming of Sheet Metals[D], Jiang Su:Nanjing University of Aeronautics and Astronautics, 2010.

[5] C. J. Su, T. Yu, Sheet Metal Forming Analysis and Application, National Defense Industry Press, Beijing, 2011.

[6] Nizhi.Qu, The Application of Numerical Simulation in the Sheet Metal Forming Limit Analysis[D], Poly technical technical University, 2007, pp.25-48.

[7] Xiao Qing .Gao, Yi.Liu, JingWei.Wang, etc, The Form Forming Limit Diagram and Application of AZ31 Magnesium Alloy Sheet in the Hot State[J], Metal Materials and Engineering, 2013, pp.550-555.

[8] Rasoul S K, Hassan M N, Cholambosein L.Forming limit diagram prediction of tailor-welded blank using experimental and numerical methods[J].Journal of Materials Engineering and Performance, 2012, pp.2053 $-2061$.
Author Profile

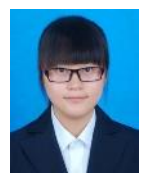

Liwen Tian received the B.S. degree in Mechanical and Electrical Engineering from Tangshan university in2013. Now is studying in Mechanical and Electrical Engineering and Tianjin Key Lab of High Speed Cutting and Precision Machining from Tianjin University of Technology and Education and will receive the M.S. degree in 2016 .

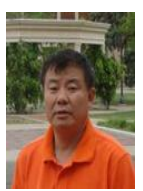

Changfeng Men is a professor and Master tutor in Mechanical and Electrical Engineering from Tianjin University of Technology and Education. His research directions are mechanical strength and material mechanics properties. $\mathrm{He}$ is the head of the class quality of mechanics of materials and excellent speaker teacher. He had to attend and complete national natural science funds, to complete a natural science fund of Tianjin, a project of Tianjin municipal education commission. In the domestic and international academic journals, he has published more than 10 international conferences, presided and completes five research projects, such as the liaohe oil field projects. 